\title{
Study on Causes of Inquisition by Torture and its Countermeasures
}

\author{
Yitong Wang ${ }^{1}$ \\ ${ }^{1}$ School of Humanities and Social, North China Electric Power University, China
}

Keywords: Inquisition by torture, Damage, Cause, Countermeasures

\begin{abstract}
Recent years, with the continuous improvement of governing by law in our country, the concept of democracy and rule of law has win support among the people. "Protection of Human Rights" is written in the new "Criminal Procedure Code” (thereinafter referred to as CPC), it attract public's attention on inquisition by torture which is a great damage to society and causing framed-up and wrong cases easily. In this paper, the author based on the unjust cases exposure recently to analysis the existing torture phenomenon and characteristics in our country, and described its causes and hazards. The paper studied how to inhibit and reduce the occurrence of this phenomenon from aspects like system construction, the guaranteed rights of criminal suspects, defendants and witnesses, interrogation process, enhance the education and management of investigators, improving quality and other aspects, expected to increase the transparency of justice, achieving the punishment adapt to the criminal to ensure social equity.
\end{abstract}

\section{Introduction}

Recent years, with the continuous improvement of legal system and the rising awareness of rule by law in our nation, the supervision on justice conduct being more widely, and media exposed some framed-up and wrong cases causing by torture such as "case of intentional homicide by Zhao Zuohai" and "case of poisoning by Qian Renfeng" and others. It shows that in the process of interrogation, the usage of corporal punishment or disguised corporal punishment and threaten is popular in investigative organs, espacially is corporal punishment. The typical one is what Qian Renfeng said to reporters from Jing Hua Times after being acquitted, "they ordered me to kneel on the ground seven or eight hours and hit on my face with the sole once I said no guilty...”

\section{Characteristics and damage of inquisition by torture}

Implement subjects.Public security officers, auxiliary police who assist the investigation and cadet police in school is the direct implementer of torture, this proves that police school should pay more attention on the cultivate of legal sense and overall quality of students in training process, and gradually improve their ideological knowledge. In addition, inquisition by torture can be quite convenience and fast to obtain evidence, which become an important reason for it can't be stopped repeatedly.

Occurrence place and time. Torture problem mostly occurred in the investigation stage, therefore, its occurrence place is mostly in the detention center and police interrogation room. And it often occurred during the first inquiry, summons and detained period by investigators. This is a supervised blind angle period, for lawyer only can be involved in after the first interrogation, thus lacking certain external oversight. And the judiciary can invented to supervise only when there is a clear problem exposed after the fact, like the suspect has obvious bruises, scars, and other signs of torture after the questioning. 
High concealment. Combining with the status quo, the frequency of using corporal punishment has been greatly reduced, replaced by flexible disguised corporal punishment, such as "standing punish, kneeling punish” in Qian Renfeng case, "knock head with a stick or putting firecrackers above" exposed in Zhao Zuohai case and "side raise, using fingers to hook toes, needle punching, noise disguise method" and other variable forms exposed in recent years. Taking "side raise” for example, investigators asked the claim or defendant to raising his hands and tight body to stand for hours when confessed. This means won't cause obvious damage on their body, but enough to causing burden and resulting spiritual repression and forcing them confessed. While without significant damage and monitoring records, the judiciary can't obtain sufficient evidence in later supervision, and hard to constraint investigating authorities' behavior only based on "one-side" opinion.

Hard to be vindicated. Various framed-up and wrong cases caused by torture are hard to be vindicated and even causing irreparable consequences once formed. Until Qian Renfeng cried his grievance thirteen years, the superior court of Yunnan province changed the original sentence, NianFu gained "not guilty” judge from Fuzhou intermediate people's court after ten sessions in eight years, and the "intentional homicide" in Zhao Zuohai case vindicated after twelve years, but resulting the family being fragmented and penniless.

Therefore, although torture has certain advantages in obtaining evidence, but generally speaking, its damage is far more serious than its rationality of existing. Its harmfulness is mainly reflected in following aspects: First, torture seriously damaged the legitimate interests of citizens, and bad for the protection of human rights, resulting miscarriage cases. It is a relentless abuses on human rights, causing great shadow on psychology of the person questioned or interrogated, leading varying degrees of body damage, and more seriously aggravation citizen's distrust in judiciary. Second, it waste a lot of judicial resources, decreased the judiciary's efficiency. Torture caused miscarriage cases, when the judiciary vindicated the cases, all the procedures carried out prior will be invalidate, increase the costs, reducing their efficiency. Third, it is against the basic pursuit value of "CPC". To start with, torture has fundamentally conflict with the basic principles of "based on law, based on facts”, and is unfavorable to achieve substantive justice. Then, CPL has its own values---procedural justice and asking "visible justice", this concept is originated from the old British legal maxim "justice not only be done, but must be done seeing" which is carried out secretly in current questioning stage, the procedure can't be fully disclosed and the procedural justice won't be guaranteed. Without the backup of procedural justice, it is hard to achieve substantive justice.

\section{Reasons of the existence of torture}

The influence of traditional concepts. First of all, our country executed 2000 years of the centralized system since Qin Dynasty, and the “rule by man” mentality has rooted deeply. The thought of "the rule of man and light human rights" functioning from feudal times until now, various dynasties "preference" the practice of torture to gain evidence in detection process. The modern "rule of man" is proposed by Enlightenment thinkers, an imported goods introduced in recent times, and the ideology of judiciary and citizens on it is still relatively weak.

Secondly, our nation upholds the concept of "presumption of guilt" rather than the principle of "presumption of innocence" until now. Adhere to the "presumption of guilt" thought, the position of the suspect is equivalent to the crime, which means that the investigators have default it's guilty before a trail. This default will causing insecure of criminal suspect's legitimate rights and interests, and in such condition, investigators will using torture means for obtain evidence sooner.

In the end, the far-reaching influence of ancient "based on oral confessions". Torture was 
originally produced in the inquisitional proceedings in Roman feudalism, China's feudal period also belongs to this model. It made investigators believe that obtain suspect's oral confession is the key point to gain crime evidence which will smooth the proceeding of clear up this case. This idea is rooted in our traditional culture and profoundly influenced our judicial practice.

The quality of investigators. First, with low quality and weak rule of law awareness, investigators are eager to obtain confessions in the beginning stage, even choosing violent means. Then, influenced by the pursuit of detection efficiency in performance evaluation, they use torture in order to conclude quickly. Last, their unqualified investigating ability and professional skill is a key influential factor.

Lacking of efficient and necessary supervisions. First, from the legislative aspect, our nation is lacking of specific provisions for the control of partial in investigation. Although torture has been affirmed crime in China's CPC, its definition is still vague. What's more, the legal punishment of this provision is relatively light, making them believed there is no serious consequences if convicted and ignored it.

Second, from the supervision aspect, defense lawyer can't effectively participate in the whole process, and lack of transparency and efficient external oversight in the interrogation session. Moreover, a large difficulty in post-supervision of the judiciary, some of the person in charge will cover and tolerate the occurrence of torture for end the case rapidly.

Third, from the institutional aspect, our country combining obtains evidence with interrogate. To start with, it would led "preconceived" idea and when the confession does not match with the investigation, investigators will not believe that statement is true and forcing suspects to disclose their expected results. Next, this institution is lacking of necessary restrictions. If learning from the experience of "power restriction” and separating investigators and interrogators, an efficiency supervision and avoiding of preconceived situation can be realized.

Effect from legal instrumentalism. Influenced by the legal instrumentalism, our nation thought law is only a tool and means to achieve political objectives, while ignoring the value of the program itself and the protection of human rights of participants in the proceedings. Therefore, investigators for the purpose of realize their perceived "substantive justice" to forcing the questioned person to confess. Only practically emphases on "protection of human rights” can us fundamentally avoiding torture phenomenon.

In the modify of CPC 2012, our country first written the law "protect the rights of people involved in litigation proceedings" as a basic principle, reflecting its value of human rights, especially the rights of criminal suspects and defendants, which is also helps to suppress the occurrence of torture.

\section{The countermeasures of suppress and reduce torture}

Research from the perspective of construction the system. Prof. Chen Ruihua once proposed the "burden of proof inversion system" in Administrative Procedure Law should be introduced into CPC, which means the court using this principle on torture problems. When the defendant and his defenders pointed out that investigators existing torture problems during the trial, the prosecutor have the responsibility to prove that torture does not exist, if they can't, the court will determine the torture does exist and the confession obtained by investigators cannot be used as legal evidence. Because in the investigate process, the suspects is in an unsettled custody state, thus the customary "the one who advocate should burden of proof" is unreasonable, for they can't proof the existence of torture. In another side, the investigative organ should ensure the process of interrogation is legal if they want use the confessions obtained, which is to say to ensure there is no torture and other 
illegal acts happened. So it is more reasonable and fair for the prosecution to bear the responsibility to prove the existence of torture.

To exert pressure on prosecution from the burden of proof responsibility aspect, they will become more cautious when adoption the appeal records and the supervision will increase, which will control of the usage of torture in interrogation.

As already mentioned above, due to the unity of the investigation and interrogation mode, the trends of occurring torture became more possible. And the separation of investigation and interrogation in our country is in the useful trying stage, which can forming an effective constraint on torture, avoiding preconceived ideas and improving efficiency.

Fulfill the illegal evidence exclusion system. China's CPC article 50 provides, "the people's courts, the people's Procuratorates and the public security organs may according to the circumstances of a case issue a warrant to compel the appearance of the criminal suspect or the defendant, order him to obtain a guarantor pending trial or subject him to residential surveillance.” This section requires prosecutors, judges strict the application of the illegal evidence exclusion system in practice. And the gain of confession by illegal procedure or don't reviewed the case once defender proposed the existence of torture, relevant persons will ascertain where the responsibility lies strictly.

Research from the angle of the rights of suspects, defendants and witnesses. The right of not be compelled self-incrimination is originated in England, which means, first, emphasizing an equal litigation relationship in criminal proceedings, limiting the power of public security and judicial, protecting the rights of criminal suspects, defendants or witnesses, opposing involuntary confessions, to highlight the law spirit; second, the suspect, defendant and witnesses enjoy the right to remain silence, the right to refuse to answer questions caught it from sin, free from coercion confession and without confession obligation which is borne by the public security and judicial; third, the statement of the suspect and defendant of the fact about the case should be out of their voluntary, involuntary statements should be excluded, and not regarded as a verdict. The introduction of this code will plays a very positive significance in restrict torture.

The right to silence refers the suspect and defendant has the right to remain silence and refuse to answer questions when questioned by public security organs or stand trial. In western criminal proceeding, the silence right is considered as one of the most important right to act self-defense in criminal prosecution. Chinese scholars hold different views on whether introduce the silence right, but I believe that only raising silence right to a legal rights, the investigating authorities will pay enough attention to human rights during interrogation, reducing the torture phenomenon. But, the universally application of silence right will increase the detection difficulties in some gross cases. Therefore a further research is needed of whether silence right applied in the major cases like drug crime, bribery and endangering national security or not.

Health inspection rights refers to the detainee have right to choose doctors to check physical health according to their own will. The selected doctor should have no interest relations with relevant staffs, applying "avoidance" system to ensure the authenticity and objectivity of the test results. This right has provided expressly in many countries' criminal procedure law. Our country has not clearly defined this right yet, but its application is very necessary.

Research from the perspective of inquiry process. Audio and video recordings are needed throughout the trial. In current judicial practice, developed areas are often choosing the method of audio and video to records on the criminal suspect's confession process of guilt, proving the authenticity of the statement. The partial monitoring records may led to blind angles and if there exists torture or not during the questioning process is unknown. Non-clip recording of the entire 
interrogation processes can provide a strong oversight on whether illegal acts exists during the questioning period, avoiding subtle and diverse means of torture, meanwhile, obtain more objective and reliable confessions.

Lawyers should involve earlier. In current stage of our country, defense lawyers are not involved in the process of whole case, they can participate in only after the first interrogation or the suspects were in custody. In recent years, legal experts and lawyers have been advocating, "to allow defense lawyers invited to join the investigators questioning suspect process. The present of defense lawyer can act as "witnesses" which can fully prove the legality of the confession obtained by investigating authorities, and also plays a supervisory role."

Strengthen the quality of investigators. First, investigators should abandon the traditional thought of "presumption of guilt", timely changing ideas. As soon as possible to implement "presumption of innocence" in practice, making the "supremacy of human rights" ideology enjoys popular support.

Second, investigators should strengthen their legal education, handling cases strictly accordance with the law, perform their duties and exercise the power in accordance with statutory authority and procedures, ascertaining the facts based on objective evidence, realizing the results comply with substantive justice, achieving procedural fairness.

Finally, investigators need to improve their handling capacity and skills. To take advantage of information technology to innovation and reform investigative techniques, obtaining investigative resources from various aspects, strengthening cross region cooperation in public security organs, enhance their investigative capacity, improving work efficiency fundamentally, establishing an ideology of "light confession, heavy facts".

\section{Conclusion}

Due to the quickness in solving cases, torture has been the "preference" of the investigation process, but the serious consequences caused by it are irreversible, which resulting miscarriages and wasting judicial resources. Anti-torture has become the world's mainstream. The "Convention on Civil and Political Rights" in 1966 and the "Convention against Torture and Other Cruel, Inhuman or Degrading Treatment or Punishment” in the United Nations Charter all clearly prohibited to obtain evidence by torture. Under the impact of global trend, China should accelerate the process of protecting human rights, eliminate torture phenomenon fundamentally, standardizing the interrogation procedures and ensure social fairness and justice.

\section{Reference}

[1] Lai, M. Jiang, J. Exploration on the systems and mechanism to prevent torture. Journal of Shanghai Institute of Political Science and Law, 2013, (4). (In Chinese)

[2] Jiang, X. Causes and control of torture. Legal System and Society 2015 (3). (In Chinese)

[3] Chen, R. Involuntary presumption of confession out of court. Legal Forum 2005 (5). (In Chinese)

[4] Zhao, B. Peng, X. experience outside of the law to curb torture and its implications. Jianghai Academic Journal 2015 (1). (In Chinese)

[5] $\mathrm{Hu}$, J. Jin, C. Study on the separating between justice criminal investigation authority and custody rights. Zhejiang Academic Journal 2001 (2). (In Chinese) 
[6] Luo, J. Trans. Code of Criminal Procedure. China Legal Publishing House 2006. (In Chinese)

[7] Criminal Law of the People's Republic of China. (In Chinese)

[8] Criminal Procedure of People’s Republic of China. (In Chinese) 